\title{
Editorial:
}

\section{Prevention is Better than Cure: Antibiotic Resistance and Management of Infectious Diseases} Mainul Haque

Keywords: Inhibition, stoppage, superior, antibiotic, antimicrobial, AMR, treatment, communicable, contagious, illness, sickness

\section{Prevention is Better than Cure: Antibiotic Resistance and Management of Infectious Diseases}

Homo sapiens are enjoying a better-quality life for the last seven to eight decades because of the invention of antimicrobials that have successfully treated many bacterial, viral, fungal, protozoan, parasitic diseases around the globe. ${ }^{1}$ The easy availability of an antibiotic has promoted a lot of overuse of this important remedial agent called 'miracle drugs' 2 all over the world, especially in lower and middle-income countries (LMICs), where, at many occasions' antimicrobials are often sold over the counter without any prescription. ${ }^{3}$ Additionally, the World Health Organization reported that around $50 \%$ of antibiotics consumption is without any definite clinical need or irrationally or imprudent. ${ }^{4}$ Microbial drug resistance is a natural phenomenon when these small creatures are in contact with antimicrobials. ${ }^{5,6}$ Although antimicrobial resistance (AMR) considered as an evolutionary process of microbes of battling antimicrobial chemotherapy, for their ultimate existence learned over billons years; nevertheless, overuse, misuse, irrational, imprudent use of antimicrobials in last 60 years enhanced the process very fast. ${ }^{7}$ It is often called "a manmade situation superimposed on nature; there is perhaps a no better example of the Darwinian notions of selection and survival." 7 Consequently, AMR is a great concern public health issue of coast-to-coast and global of the present time and is expected to persist for a long time. Antimicrobial resistance is intensifying in a geometric progression that increases statistically significantly treatment-related expenses, both for individuals and of community, morbidity, and mortality. Additionally, the situation getting worse because almost no new antimicrobials are in the pipeline to appear in the market very soon to counter the AMR..${ }^{1,89}$ Currently, the situation AMR is horrifying as almost all available antibiotics or antimicrobials for clinical use are resistant. Even the last resort for infectious diseases the colistin similarly resistant. ${ }^{10-13}$ Mobile colistin gene (MCR) has nine different varieties and located all over the planet within a few years' time..$^{14,15}$

Now-a days, it has been advised that infection evasion is much significant than to treat pathogenic infectious diseases. ${ }^{16,17}$ Thus, it recalls the famous English quote, "prevention is better than cure." All health professionals must prescribe antimicrobials only on documentary evidence infection, ${ }^{18,19}$ and effort need enhance to minimize utilization of antimicrobials by averting healthcare-associated infections (HCAIs) as infection should not occur primarily and to stop transmission. ${ }^{20,21}$ Global Alliance for Infections in Surgery advised seven stratagems to avert HCAIs. ${ }^{22}$ Those policy and planning are "patient safety, following guidelines, antibiotic stewardship, surveillance, screening and cohorting patients, environmental hygiene, and hand hygiene." 22 Prevention antibiotic resistance, especially in LMICs antibiotic stewardship and hand hygiene, are the most effective and equally cost-saving strategies. ${ }^{23,24}$ Antibiotic stewardship and hand hygiene both involve very-low budgetary issues to prevent antimicrobial resistance and management of infectious diseases; consequently, more suitable for resource-poor countries. ${ }^{25,26}$ Although multiple studies have been recommended that multidisciplinary approaches are required for preventing infectious diseases and to avert antibiotic resistance. ${ }^{9,27,28}$ The society for healthcare

Correspondence to: Mainul Haque, Professor of the Unit of Pharmacology, Faculty of Medicine and Defence Health, Universiti Pertahanan Nasional Malaysia, (National Defence University of Malaysia), Kem Perdana Sungai Besi, 57000 Kuala Lumpur, Malaysia. Email: runurono@gmail.com 
epidemiology of America denotes antibiotic stewardship as "a set of coordinated strategies to improve the use of antimicrobial medications with the goal of enhancing patient health outcomes, reducing resistance to antibiotics, and decreasing unnecessary costs." ${ }^{29}$ Additionally, multiple studies revealed that execution of an antibiotic stewardship modus operandi as a constituent of an infection prevention program was correlated with a decline rate of resistance gram-negative HCAIs in intensive care units (ICU), statistically significant outcome of treatment, diminished hospital and ICU duration of stay, individual and institutional costs of treatment, and minimized overall 30day mortality. ${ }^{30-32}$ Hand washing is one of the oldest methods of infection prevention strategies and was introduced in obstetrics practice in the last century. ${ }^{20,33-35}$ The Hungarian obstetrician Professor (Dr.) Ignaz Phillip Semmelweis first introduced chlorinated lime hand washing strategies in 1847 among obstetric hospital staffs that resulted in large improvements in maternal mortality rates by a significant reduction of puerperal sepsis. ${ }^{35,36}$ In a similar time in the USA,
Dr. Oliver Wendell Holmes implemented hand washing among health care workers (HCWs) to combat puerperal fever. ${ }^{35,37}$ Both Dr. Semmelweis and Dr. Wendell believed that contaminated HCWs hand introduces infection from one patient to another. ${ }^{35,38,39}$ Afterward, multiple studies around the sphere documented that hand washing itself reduces infection rate significantly and prevent antibiotic resistance. ${ }^{20,35,40-42}$ Thereafter, LMICs like Bangladesh should adopt at least stringent handwashing and antibiotic stewardship policy and planning with stringent regulatory measures to prevent infectious diseases antimicrobials resistance, to total stoppage of over-the-counter antibiotic sale and promote prudent utilization of antimicrobials currently available in market through prescription only medicine.

\section{Conflict of Interest}

The author does not possess any conflict of interest.

\section{Funding}

This manuscript did not receive any financial support. 
International Journal of Human and Health Sciences Vol. 04 No. 02 April'20

\section{References:}

1. Kiernan M. Prevention is better than cure: The role of infection prevention in the control of antimicrobial resistance. J Infect Prev. 2017;18(6):275-276.

2. Col NF, O'Connor RW. Estimating worldwide current antibiotic usage: report of Task Force 1. Rev Infect Dis. 1987;9(Suppl 3):S232-243.

3. Ayukekbong JA, Ntemgwa M, Atabe AN. The threat of antimicrobial resistance in developing countries: causes and control strategies. Antimicrob Resist Infect Control. 2017;6:47.

4. World Health Organization. WHO Report on Surveillance of Antibiotic Consumption 2016 - 2018 Early implementation. 2018. Available at https:// www.who.int/medicines/areas/rational use/whoamr-amc-report-20181109.pdf [Accessed November 17, 2019]

5. Sharma C, Rokana N, Chandra M, Singh BP, Gulhane RD, Gill JPS, Ray P, Puniya AK, Panwar H. Antimicrobial Resistance: Its Surveillance, Impact, and Alternative Management Strategies in Dairy Animals. Front Vet Sci. 2018;4:237.

6. Prestinaci F, Pezzotti P, Pantosti A. Antimicrobial resistance: a global, multifaceted phenomenon. Pathog Glob Health. 2015;109(7):309-318.

7. Davies J, Davies D. Origins and evolution of antibiotic resistance. Microbiol Mol Biol Rev. 2010;74(3):417433.

8. Jasovský D, Littmann J, Zorzet A, Cars O. Antimicrobial resistance-a threat to the world's sustainable development. Ups J Med Sci. 2016;121(3):159-164.

9. Aslam B, Wang W, Arshad MI, Khurshid M, Muzammil S, Rasool MH, Nisar MA, Alvi RF, Aslam MA, Qamar MU, Salamat MKF, Baloch Z. Antibiotic resistance: a rundown of a global crisis. Infect Drug Resist. 2018;11:1645-1658.

10. Duval RE, Grare M, Demoré B. Fight Against Antimicrobial Resistance: We Always Need New Antibacterials but for Right Bacteria. Molecules. 2019;24(17):3152.

11. Jacquier H, Le Monnier A, Carbonnelle E, Corvec S, Illiaquer M, Bille E, Zahar JR, Jauréguy F, Fihman V, Tankovic J, Cattoir V, GMC Study Group. In vitro antimicrobial activity of "last-resort" antibiotics against unusual nonfermenting Gram-negative bacilli clinical isolates. Microb Drug Resist. 2012;18(4):396-401.

12. Nusrat T, Haque M. Mobile Colistin Resistance (MCR) Gene, Antimicrobial Resistance: A Global Public Health Threat. Bang J Med Sci. 2020;19 (1):5-
10.

13. Haque M, Rahman NAA, McKimm J, Kibria GM, Azim Majumder MA, Haque SZ, Islam MZ, Binti Abdullah SL, Daher AM, Zulkifli Z, Rahman S, Kabir R, Lutfi SNNB, Aishah Binti Othman NS. Self-medication of antibiotics: investigating practice among university students at the Malaysian National Defence University. Infect Drug Resist. 2019;12:1333-1351.

14. Wang X, Wang Y, Zhou Y, Wang Z, Wang Y, Zhang S, Shen Z. Emergence of Colistin Resistance Gene mcr8 and Its Variant in Raoultella ornithinolytica. Front Microbiol. 2019;10:228.

15. Wang X, Wang Y, Zhou Y, Li J, Yin W, Wang S, Zhang $\mathrm{S}$, Shen J, Shen Z, Wang Y. Emergence of a novel mobile colistin resistance gene, mcr-8, in NDMproducing Klebsiella pneumoniae. Emerg Microbes Infect. 2018;7(1):122.

16. National Institutes of Health(US); Biological Sciences Curriculum Study. NIH Curriculum Supplement Series [Internet]. Bethesda (MD): National Institutes of Health (US); 2007. Understanding Emerging and Re-emerging Infectious Diseases. Available at https:// www.ncbi.nlm.nih.gov/books/NBK20370/[Accessed November 17, 2019]

17. Peterson JW. Bacterial Pathogenesis. In: Baron S, editor. Medical Microbiology. 4th edition. Galveston (TX): University of Texas Medical Branch at Galveston; 1996. Chapter 7. Available at https:// www.ncbi.nlm.nih.gov/books/NBK8526/ [Accessed November 17, 2019]

18. Nair M, Tripathi S, Mazumdar S, Mahajan R, Harshana A, Pereira A, Jimenez C, Halder D, Burza S. Knowledge, attitudes, and practices related to antibiotic use in Paschim Bardhaman District: A survey of healthcare providers in West Bengal, India. PLoS One. 2019;14(5):e0217818.

19. Pulcini C, Gyssens IC. How to educate prescribers in antimicrobial stewardship practices? Virulence. 2013;4(2):192-202.

20. Mehta Y, Gupta A, Todi S, Myatra S, Samaddar DP, Patil V, Bhattacharya PK, Ramasubban S. Guidelines for prevention of hospital-acquired infections. Indian J Crit Care Med. 2014;18(3):149163.

21. Llor C, Bjerrum L. Antimicrobial resistance: risk associated with antibiotic overuse and initiatives to reduce the problem. Ther Adv Drug Saf. 2014;5(6):229-241.

22. Global Alliance for Infections in Surgery. 7 strategies 
International Journal of Human and Health Sciences Vol. 04 No. 02 April'20

to prevent healthcare-associated infections. Available at https://infectionsinsurgery.org/7-strategiesto-prevent-healthcare-associated-infections-2/ [Accessed November 18, 2019]

23. Bebell LM, Muiru AN. Antibiotic use and emerging resistance: how can resource-limited countries turn the tide? Glob Heart. 2014;9(3):347-358.

24. Lemmen SW, Lewalter K. Antibiotic stewardship, and horizontal infection control are more effective than screening, isolation, and eradication. Infection. 2018;46(5):581-590.

25. Storr J, Twyman A, Zingg W, Damani N, Kilpatrick C, Reilly J, Price L, Egger M, Grayson ML, Kelley E, Allegranzi B; WHO Guidelines Development Group. Core components for effective infection prevention and control programs: new WHO evidence-based recommendations. Antimicrob Resist Infect Control. 2017;6:6.

26. HM Government. Tackling antimicrobial resistance 2019-2024. The UK's five-year national action plan. 2019. Available at https://assets.publishing. service.gov.uk/government/uploads/system/uploads/ attachment_data/file/784894/UK_AMR_5 year national_action_plan.pdf [Accessed November 18, 2019]

27. Uchil RR, Kohli GS, Katekhaye VM, Swami OC. Strategies to combat antimicrobial resistance. J Clin Diagn Res. 2014;8(7):ME01-ME4.

28. Guillemot D, Courvalin P. Better Control of Antibiotic Resistance. Clinical Infectious Diseases. 2001;33(4):542-547.

29. The Society for Healthcare Epidemiology of America. Antimicrobial Stewardship. 2019. Available at https:// www.shea-online.org/index.php/practice-resources/ priority-topics/antimicrobial-stewardship [Accessed November 18, 2019]

30. Dortch MJ, Fleming SB, Kauffmann RM, Dossett LA, Talbot TR, May AK. Infection reduction strategies, including antibiotic stewardship protocols in surgical and trauma intensive care units, are associated with reduced resistant gram-negative healthcare-associated infections. Surg Infect (Larchmt). 2011;12(1):15-25.

31. Perez KK, Olsen RJ, Musick WL, Cernoch PL, Davis JR, Peterson LE, Musser JM. Integrating rapid diagnostics and antimicrobial stewardship improves outcomes in patients with antibiotic-resistant Gramnegative bacteremia. J Infect. 2014;69(3):216-25.
32. Lai CC, Shi ZY, Chen YH, Wang FD. Effects of various antimicrobial stewardship programs on antimicrobial usage and resistance among common gram-negative bacilli causing healthcare-associated infections: A multicenter comparison. J Microbiol Immunol Infect. 2016;49(1):74-82.

33. Mathur P. Hand hygiene: back to the basics of infection control. Indian J Med Res. 2011;134 (5):611-620.

34. Hammerschmidt J, Manser T. Nurses' knowledge, behavior, and compliance concerning hand hygiene in nursing homes: a cross-sectional mixed-methods study. BMC Health Serv Res. 2019;19(1):547.

35. Haque M, Sartelli M, McKimm J, Abu Bakar M. Healthcare-associated infections - an overview. Infect Drug Resist. 2018;11:2321-2333.

36. Noakes TD, Borresen J, Hew-Butler T, Lambert MI, Jordaan E. Semmelweis and the etiology of puerperal sepsis 160 years on: an historical review. Epidemiol Infect. 2008;136(1):1-9.

37. WHO Guidelines on Hand Hygiene in Health Care: First Global Patient Safety Challenge Clean Care Is Safer Care. Geneva: World Health Organization; 2009. 4. Historical perspective on hand hygiene in health care. Available at https://www.ncbi.nlm.nih. gov/books/NBK144018/ [Accessed November 18, 2019]

38. Pittet D, Boyce JM. Hand hygiene and patient care: pursuing the Semmelweis legacy. Lancet. 2001;1:9-20.

39. Sharma R, Sharma M, Koushal V. Compliance to hand hygiene world health organization guidelines in-hospital care. Int J Prev Med. 2014;5(1):127-128.

40. Fair RJ, Tor Y. Antibiotics and bacterial resistance in the 21 st century. Perspect Medicin Chem. 2014;6:2564.

41. Collins AS. Preventing Health Care-Associated Infections. In: Hughes RG, editor. Patient Safety and Quality: An Evidence-Based Handbook for Nurses. Rockville (MD): Agency for Healthcare Research and Quality (US); 2008 Apr. Chapter 41. Available at https://www.ncbi.nlm.nih.gov/books/NBK2683/ [Accessed November 18, 2019]

42. Larson EL, Quiros D, Giblin T, Lin S. Relationship of antimicrobial control policies and hospital and infection control characteristics to antimicrobial resistance rates. Am J Crit Care. 2007;16(2):110-120. 